Vol. 18 (2009): 136-143.

\title{
Genetic stability of wild pear (Pyrus pyraster, Burgsd) after cryopreservation by encapsulation dehydration
}

\author{
Emiliano Condello, Maria Antonietta Palombi, Maria Grazia Tonelli, Carmine Damiano \\ and Emilia Caboni* \\ CRA - Fruit Tree Research Center, Via di Fioranello, 5200134 Rome - ITALY \\ *email:e.caboni@propag.org
}

\begin{abstract}
Shoot tips of Pyrus pyraster were successfully cryopreserved by encapsulation-dehydration. Na--alginate beads each containing one shoot tip, dehydrated for 2 days in $0.75 \mathrm{M}$ sucrose and desiccated to $20 \%$ moisture content (fresh weight basis), gave $60 \%$ recovery after exposure to liquid nitrogen. Regenerated shoots showed no differences in length and leaf shape compared to the mother plant. Multiplication rate and rooting ability of cryopreserved shoots were lower than those of untreated controls after one subculture, but were completely restored following the third subculture. Fifteen cryopreserved lines derived from single buds were used for genetic analyses by RAPDs and SSRs, in comparison with the mother plant. In RAPD analysis, of a total of 24 primers, only 15 showed reproducible and well resolved bands and were further used. These primers produced a total of 66 fragments ranging from about 500 to 2500 base pair size. SSR (microsatellite) marker amplification was performed using 19 primers which produced 57 reproducible fragments. Microsatellites fragments ranged from 60 to 600 base pairs. Both RAPDs and SSRs did not reveal any polymorphism between cryopreserved lines and the original genotype, suggesting that cryopreservation, using encapsulation-dehydration, does not affect genetic stability of wild pear.
\end{abstract}

Key-words: germplasm preservation, multiplication ability, RAPDs, rooting, somaclonal variation, SSRs, tissue culture. 
Vol. 18 (2009): 136-143.

\section{Introduction}

In situ plant germplasm preservation plays an important role in the maintenance of biodiversity and the avoidance of genetic erosion, but the preservation of woody species in field gene banks requires huge land areas and it is expensive (Panis and Lambardi 2005). Cryopreservation is an alternative choice for the long-term conservation of germplasm including woody fruit species and their wild relatives (Engelman 2004). In recent years, several new techniques have been developed for the cryopreservation of shoot tips of tropical and temperate plant species. The encapsulation-dehydration method, originally described for cryopreservation of Solanum shoot tips (Fabre and Dereuddre 1990), has been also successfully applied to cryopreserve shoot tips of several fruit tree species (Gonzalez-Arnao and Engelmann 2006), including Pyrus (Dereuddre et al. 1990, Niino and Sakai 1992), Prunus (Shatnawi et al. 1999), Malus (Niino and Sakai 1992, Paul et al. 2000, Wu et al. 2001b), Vitis and Actinidia (Plessis et al. 1993, Wu et al. 2001a).

Pyrus pyraster is considered an important wild relative of cultivated pear (Pyrus communis L.). The tree is considerable in size and diameter and its high quality wood makes this species interesting for reforestation of marginal farmland and for the production of highly valued timber (Kleinschmitt et al. 1998). In cultivated regions with calcareous soils, where Fe-chlorosis is a serious problem, wild pear can be also preferred as rootstock for pear cultivars. The species is indigenous in nearly all Europe, except in the northern countries, but it is now seriously endangered (Kleinschmitt et al. 1998) and cryopreservation, being less labour requiring, could represent an alternative and/or complementary method to the in field collection and to the in vitro slow-growth conservation of this species.

The applicability of cryogenic protocols depends not only on the ability to survive, but also on the assumption of obtaining recovered material without any genetic modification with respect to the starting genotype. Various studies with molecular markers have been performed to asses somaclonal variation in cryopreserved plant material (Hard- ing 2004, Harding et al. 2005, Helliot et al. 2002). Among the DNA analysis techniques used, randomly amplified polymorphic DNA (RAPD) and simple sequence repeat (SSR) analysis have also been applied to evaluate genetic stability of the material surviving cryopreservation and in most of the cases have not provided evidence for genetic variation. When DNA polymorphisms were detected, they were considered as results of the culture-cryoprotection-regeneration process and not of the cryopreservation by itself (Harding 2004). However, in a recent work the encapsulation-dehydration method was shown, even at very low rate, to induce somaclonal variability in chrysanthemum (Martín and Gonzáles-Benito 2005).

The present study evaluates the genetic stability in wild pear cryopreserved by the encapsulationdehydration method through RAPD and SSR analyses. Morphological (shoot length and leaf shape) and physiological parameters (multiplication and rooting ability) were also studied to characterize the cryopreserved cultures.

\section{Materials and methods}

\section{Plant material}

In vitro propagated cultures, obtained from a single axillary bud of a wild pear (Pyrus pyraster, Burgsd) genotype, were established according to Caboni et al. (1999).

Shoots in the proliferation phase were subcultured every 21 days on a medium ("LPmod" medium) consisting of LP (Quoirin and Lepoivre 1977) salts and the following organics: $0.5 \mathrm{mg}$ $\mathrm{L}^{-1}$ nicotinic acid, $0.5 \mathrm{mg} \mathrm{L}^{-1}$ pyridoxine, $2.0 \mathrm{mg}$ $\mathrm{L}^{-1}$ glycine, $0.5 \mathrm{mg} \mathrm{L}^{-1}$ thiamine- $\mathrm{HCl}, 150 \mathrm{mg} \mathrm{L}^{-1}$ myo-inositol, $1.0 \mathrm{mg} \mathrm{L}^{-1}$ Ca-pantothenate, $0.1 \mathrm{mg}$ $\mathrm{L}^{-1}$ biotin and $0.5 \mathrm{mg} \mathrm{L}^{-1}$ riboflavin, according to Caboni et al. (1999). The medium was also supplemented with $1.78 \mu \mathrm{M}$ benzyladenine (BA), 0.25 $\mu \mathrm{M}$ indole-3-butyric acid (IBA), $20 \mathrm{~g} \mathrm{~L}^{-1}$ sucrose and $6 \mathrm{~g} \mathrm{~L}^{-1}$ agar (B \& V - Italy). The $\mathrm{pH}$ was adjusted to 5.7 before sterilization and cultures were 
Condello, E. et al. Cryopreservation and genetic stability in wild pear

maintained at $25^{\circ} \mathrm{C}$ under a $16 \mathrm{~h}$ photoperiod and a light intensity of $40 \mu \mathrm{mol} \mathrm{m} \mathrm{m}^{-2} \cdot \mathrm{s}^{-1}$ provided by cool white fluorescent tubes (Philips TLD - France).

\section{Cryopreservation protocol}

Mother plants were cold acclimatized for 2 weeks in darkness at $5{ }^{\circ} \mathrm{C}$. Subsequently, shoot tips $(2-4 \mathrm{~mm}$ in length) were excised and sub-cultured for $24 \mathrm{~h}$ on the LPmod medium containing $0.3 \mathrm{M}$ sucrose. Apices were then transferred to MS (Murashige and Skoog 1962) calcium free liquid medium, supplemented with $3 \%$ alginate (Sigma). Beads were prepared by dispensing drops of alginate medium, each one containing one shoot tip, in a $100 \mathrm{mM} \mathrm{CaCl}_{2} \mathrm{MS}$ liquid medium. The beads formed were cultured in liquid LPmod containing $0.75 \mathrm{M}$ sucrose for 2 days, desiccated in vessel containing silica gel ( 5 beads in $18 \mathrm{~g}$ ) to a bead moisture content of $20 \%$ fresh weight, placed in $1 \mathrm{ml}$ cryo-vials (Nalgene, 10 beads in each cryovial) and immersed in liquid nitrogen where they were kept for 1 week. Beads were then directly transferred to Petri dishes containing $0.3 \mathrm{M}$ sucrose enriched LPmod medium in darkness at room temperature and finally transferred to the standard multiplication medium and sub-cultured regularly, as reported above.

\section{Morphological observations, multiplication and rooting performance evaluation}

Thirty days after recovery, necessary to overcome an initial lag phase in growth after storage in liquid nitrogen, 30 single shoots were transferred to standard proliferation conditions reported above for morphological and multiplication ability evaluation, in comparison with 30 shoots obtained from shoot tips of the mother plant. Multiplication rates (final number of shoots - initial number of shoots divided by initial number of shoots) were calculated and shoot length and leaf shape were evaluated in newly formed shoots. Data were collected at the end of the $1^{\text {st }}$ and $3^{\text {rd }}$ subculture.
For rooting experiments, 30 microcuttings were immersed for 5 days in a $2 \mathrm{mg} \mathrm{L}^{-1}$ IBA solution plus $20 \mathrm{~g} \mathrm{~L}^{-1}$ sucrose in the darkness and then transferred to a hormone free LPmod medium and to the light. Data were collected 30 days after the beginning of the root induction treatment. The experiment was repeated after three subcultures. Data (percentages were transformed to arc-sin root before analysis) were subjected to analysis of variance and differences among means were compared by Fisher's test.

\section{RAPD and SSR analysis}

Fifteen of the recovered shoots were cultured separately and these lines were used for molecular analyses. Genetic stability of the 15 lines was tested, in comparison with the mother plant, using 24 RAPD primers, designed according to Williams et al. (1990) and 19 SSR primer pairs, previously selected in Yamamoto et al. (2002) for giving unambiguous and reproducible fragment patterns in pear. Total DNA was extracted from $100 \mathrm{mg}$ of plant tissue with DNeasy Plant Mini Kit (Quiagen). Two independent extractions were performed for each line and for the control (mother plant). RAPD reactions were carried out in a volume of $30 \mu \mathrm{l}$ containing $25 \mathrm{ng}$ total DNA, 1X PCR buffer (Qiagen), $1.5 \mathrm{mM} \mathrm{MgCl}_{2}$, $200 \mu \mathrm{M}$ dNTPs, $0.4 \mu \mathrm{M}$ 10-mer oligonucleotide primer (Invitrogen) and 1 U Taq polymerase (Qiagen). SSR amplifications were performed in a volume of $30 \mu$ containing $25 \mathrm{ng}$ total DNA, 1X PCR buffer (Qiagen), $2.3 \mathrm{mM} \mathrm{MgCl}_{2}, 200 \mu \mathrm{M}$ dNTPs, $0.3 \mu \mathrm{M}$ oligodeoxynucleotide primers (Invitrogen) and $1 \mathrm{U}$ Taq polymerase (Qiagen). DNA amplifications were performed in a Biometra $\mathrm{T}$ thermal cycler with a preliminary step of $5 \mathrm{~min}$ at $94{ }^{\circ} \mathrm{C}, 45$ cycles of 60 s at $94{ }^{\circ} \mathrm{C}, 60 \mathrm{~s}$ at $36{ }^{\circ} \mathrm{C}$ and $2 \mathrm{~min}$ at $72{ }^{\circ} \mathrm{C}$ and a final step of $5 \mathrm{~min}$ at $72^{\circ} \mathrm{C}$ for RAPDs. For SSRs, an initial step of $5 \mathrm{~min}$ at $94{ }^{\circ} \mathrm{C}$, followed by 35 cycles of $1 \mathrm{~min}$ at $94{ }^{\circ} \mathrm{C}, 1 \mathrm{~min}$ at $55-58^{\circ} \mathrm{C}$ and 2 min at $72{ }^{\circ} \mathrm{C}$ and a final $5 \mathrm{~min}$ extension at $72{ }^{\circ} \mathrm{C}$ were performed. In order to obtain reproducible and clear DNA fragment patterns, each amplification was repeated twice. RAPD amplification products were separated in a $1.5 \%$ agarose (Duchefa-NL) gel using 


\section{AGRICULTURAL AND FOOD SCIENCE}

\section{Vol. 18 (2009): 136-143.}

1X TBE buffer and stained with ethidium bromide. SSR fragments were analysed on 3.5\% MetaPhor agarose (Cambrex Bio Science - USA) gel in $1 \mathrm{X}$ TBE buffer and stained with ethidium bromide.

\section{Results}

After cryopreservation the survival rate of the explants was $60 \%$ (Fig. 1), they grew well, developed normally and, compared with the control, no morphological differences were observed (Fig. 2; Table 1). Multiplication rate and rooting ability of the cryopreserved shoots were lower than those of the control after one subculture, but were completely restored after three subcultures (Table 1).

In order to evaluate if the encapsulation dehydration method preserves genetic integrity in wild pear, we used RAPD and SSR markers for the molecular analysis. To increase the confidence of the analysis, we selected only those primers which gave very reproducible bands. In RAPD analysis, a total of 24 primers were firstly used to amplify DNA of all genotypes and with 15 of them we obtained reproducible and well resolved bands and they were selected for further use (Table 2). These primers produced a total of 66 fragments ranging from about 500 to 2500 base pairs in size. The highest number of analysable bands was obtained with the primers 70.13 and 70.20 (six fragments each), the lowest with the primer 70.15 (one fragment).

SSR marker amplification was performed using 19 primers that produced 57 reproducible fragments (Table 3). Fragments ranged from 60 to 600

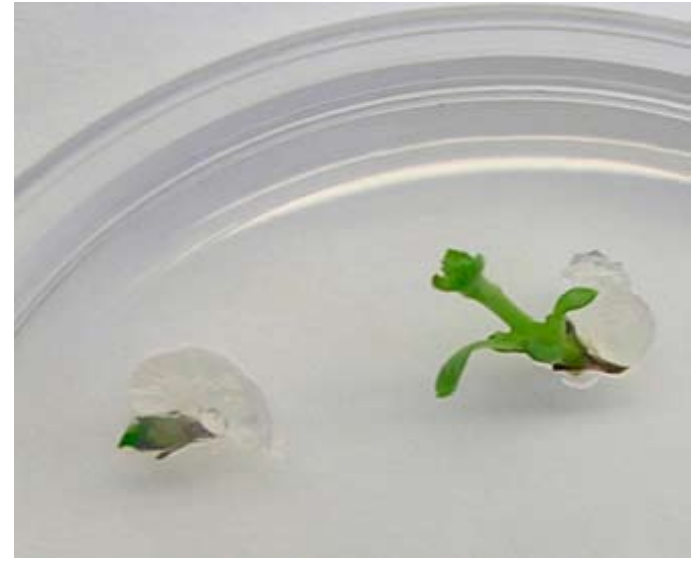

Fig. 1. Wild pear shoots encapsulated in alginate beads and recovered after cryopreservation.

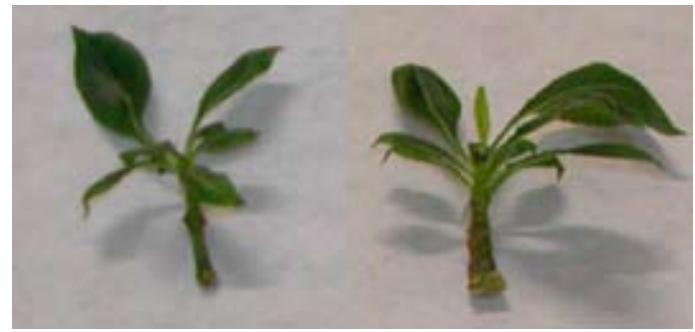

Fig. 2. Wild pear shoot, 30 days after recovery from cryopreservation (left) and mother plant shoot

base pairs; the highest number of analyzable bands was obtained with the primer pair $\mathrm{NH} 020$ (six fragments), the minimum with primer pair NB103 (one fragment). A summary of the results of RAPD and SSR marker analysis is given in Tables 2 and 3. The total number of fragments scored for the whole plant material analysed was 1056 (66 fragments

Table 1. Shoot length, leaf shape, proliferation (MR, multiplication rate) and rooting (\% of rooted explants) ability in cryopreserved and control (mother plant) shoots after one or three sub-cultures (sc)

\begin{tabular}{lcccccccc}
\hline & \multicolumn{2}{c}{ Shoot length } & \multicolumn{2}{c}{ Leaf shape } & \multicolumn{2}{c}{ MR } & \multicolumn{3}{c}{ Rooting \% } \\
& $1 \mathrm{sc}$ & $3 \mathrm{sc}$ & $1 \mathrm{sc}$ & $3 \mathrm{sc}$ & $1 \mathrm{sc}$ & $3 \mathrm{sc}$ & $1 \mathrm{sc}$ & $3 \mathrm{sc}$ \\
\hline Cryo-shoots & $3.1 \mathrm{a}$ & $3.3 \mathrm{a}$ & stand & stand & $2.4 \mathrm{a}$ & $5.6 \mathrm{a}$ & $24.4 \mathrm{a}$ & $66.6 \mathrm{a}$ \\
Control & $3.4 \mathrm{a}$ & $3.2 \mathrm{a}$ & stand & stand & $5.4 \mathrm{~b}$ & $5.6 \mathrm{a}$ & $62.4 \mathrm{~b}$ & $68.7 \mathrm{a}$ \\
\hline
\end{tabular}

*Stand, expanded leaves of standard obvoidal form. Means on the column followed by the same letters are not significantly different at $\mathrm{p}=0.05$. Percentage data were transformed to arc-sin root before statistical analysis. 


\section{AGRICULTURAL AND FOOD SCIENCE}

Condello, E. et al. Cryopreservation and genetic stability in wild pear

$\times 16$ samples, included the control) and 912 (57 fragments $\times 16$ samples, included the control) for RAPD and SSR markers, respectively. Identical patterns were obtained with both markers when cryopreserved plantlets were compared with the mother plant (control plant) (Fig. 3 and 4).

Table 2. RAPD primers used for DNA amplification and total fragments scored.

\begin{tabular}{ccc}
\hline $\begin{array}{c}\text { RAPD } \\
\text { primers }\end{array}$ & Sequence 5'-3' & $\begin{array}{c}\text { Total fragments } \\
\text { scored }\end{array}$ \\
\hline 70.2 & CACAGGCGGA & 4 \\
70.4 & CCCGCTACAC & 5 \\
70.5 & CAAAGGGCGG & 5 \\
70.7 & AAGTGCACGG & 4 \\
70.9 & AACGGGCGTC & 4 \\
70.12 & GGCCTACTCG & 3 \\
70.13 & GTGTCGCGAG & 6 \\
70.15 & GCCCTCTTCG & 1 \\
70.17 & GAGACCTCCG & 5 \\
70.19 & GCTCTCACCG & 5 \\
70.20 & TGCACGGACG & 6 \\
70.22 & GTCGCCGTCA & 5 \\
70.23 & TTGGCACGGG & 3 \\
70.24 & GTGTGCCCCA & 5 \\
70.30 & CGCGCTACGT & 5 \\
\hline & & 5 \\
\hline
\end{tabular}

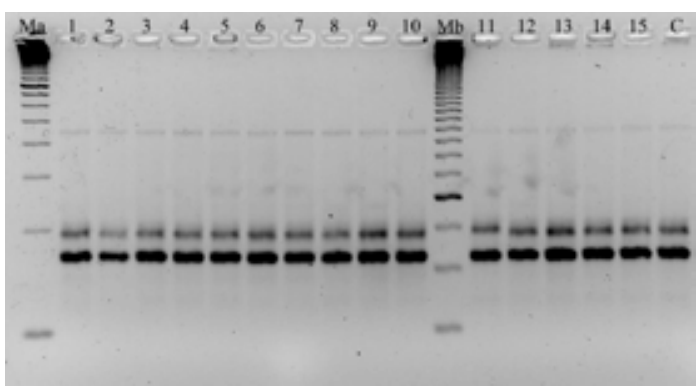

Fig. 3. RAPD banding profiles of DNA samples from mother plant (control, C) and cryopreserved shoots (1-15) of Pyrus pyraster. Amplification products were generated by primer 70.8. M: HyperLadder II (Bioline) marker.
Table 3. SSR primers, annealing temperatures used for DNA amplification and the total number of fragments scored.

\begin{tabular}{ccc}
\hline $\begin{array}{c}\text { SSR primer } \\
\text { couples }\end{array}$ & $\begin{array}{c}\text { Annealing } \\
\text { Temperature }\left({ }^{\circ} \mathrm{C}\right)\end{array}$ & $\begin{array}{c}\text { Total of scored } \\
\text { fragments }\end{array}$ \\
\hline $\mathrm{NB102}$ & 55 & 2 \\
$\mathrm{NB} 103$ & 55 & 1 \\
$\mathrm{NB105}$ & 55 & 5 \\
$\mathrm{NB} 106$ & 55 & 3 \\
$\mathrm{NB} 109$ & 55 & 4 \\
$\mathrm{NB} 110$ & 55 & 2 \\
$\mathrm{NB} 111$ & 55 & 4 \\
$\mathrm{NB} 113$ & 58 & 2 \\
$\mathrm{NH} 019$ & 55 & 2 \\
$\mathrm{NH} 020$ & 55 & 6 \\
$\mathrm{NH} 021$ & 55 & 3 \\
$\mathrm{NH} 022$ & 58 & 2 \\
$\mathrm{NH} 023$ & 55 & 4 \\
$\mathrm{NH} 024$ & 55 & 3 \\
$\mathrm{NH} 025$ & 58 & 3 \\
$\mathrm{NH} 026$ & 55 & 3 \\
$\mathrm{NH} 027$ & 55 & 2 \\
$\mathrm{NH} 029$ & 58 & 3 \\
$\mathrm{NH} 030$ & 58 & 3 \\
\hline
\end{tabular}

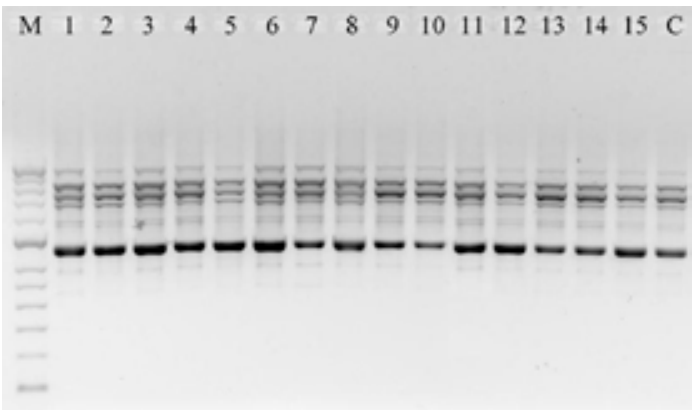

Fig. 4. SSR profiles of DNA samples from mother plant (control, C) and cryopreserved shoots (1-15) of Pyrus pyraster. Amplification products were generated by primer couple NH030 FW-NH030 RW. Ma: 50 bp ladder marker and $\mathrm{Mb}: 100$ bp ladder (Amersham-Pharmacia)marker. 
Vol. 18 (2009): 136-143.

\section{Discussion}

Conservation of plant genetic resources has to rely on methods that not only allow to obtain good survival, but also to guarantee that material remains genetically stable after conservation. Some of the steps involved in cryopreservation, putatively causing stress responses, may induce genetic instability (Engelmann 2004). For this reason, evaluation of genetic variation in cryopreserved material is an essential step before the large scale use of the established storage protocols.

In this study we used morphological, physiological and molecular markers to evaluate stability of preserved material. Similarly to Liu and co-workers (2004), who evaluated cryopreserved apple, we did not observe any morphological difference between leaf shape of the mother plant and of the cryopreserved wild pear shoots and, while multiplication and rooting ability was lower after one sub-culture, they were fully restored after three subcultures. Rooted microcuttings were acclimatised and they are now under further observation in the greenhouse.

Most of the studies previously performed have shown that the cryopreservation process does not affect genetic stability of the stored lines. Nevertheless, genetic variation was recently shown to be induceable by the encapsulation-dehydration method in Dendrathema grandiflora (Martin and González-Benito 2005) suggesting that attention should be paid to the evaluation of the genetic stability in cryopreserved lines.

In this study, we used RAPDs and SSRs to evaluate the genetic stability of the cryopreserved lines. These markers, both visualised by PCR (Polymerase Chain Reaction) and agarose-based electrophoresis, offer the advantage of being less expensive and quicker to be performed than RFLP or AFLP (Lanham and Brennan 1999, Powell et al. 1996). RAPDs, in particular, have been widely used to evaluate genetic stability in tissue cultures (Carvalho et al. 2004, Palombi et al. 2007 and references therein) and they have been also adopted to evaluate stability of cryopreserved material in various species (Hao et al. 2002, Ryynanen and
Aronen, 2005, Zhai et al. 2003, Ventkatachalam et al. 2007). SSR markers allow screening of different regions of the genome than RAPDs, including repetitive and hypervariable DNA regions and they were shown to be valuable molecular tools for determining somaclonal variation in tissue culture (Rahman and Rajora 2001) and for genetic fingerprinting of fruit tree species, pear included (Yamamoto et al. 2002). Thus, RAPDs and SSRs, showing a different polymorphism capability, can be conveniently used, in combination, to evaluate somaclonal variability induced by tissue culture (Palombi and Damiano 2002).

In our study we used 15 RAPD primers to amplify DNA of 15 cryopreserved lines and of the mother plant. These primers produced a total of 66 fragments and the total number of bands considering all the plant material analysed was 1056 . No differences were found between the wild pear lines and the mother plant in the number of fragments obtained, as also found in most of the works performed on genetic stability of cryopreserved material (Dixit et al. 2003, Sales et al. 2001, Zhai et al. 2003).

SSR marker amplification was also performed using 19 primer pairs that produced 57 reproducible bands corresponding to a total number of 912 fragments in the analysed material. Also this method showed no differences between the cryopreserved lines and the mother plant.

This is, to our knowledge, the first report on the combined application of RAPDs and SSRs for evaluation of genetic stability in cryopreserved lines of fruit trees. We analysed a total of 1968 fragments (from RAPD and SSR markers) without observing any genetic variation. This number of analysed fragments, can be considered to be informative, as reported in other studies performed on genetic stability of cryopreserved materials (Dixit et al. 2003, Sales et al. 2001, Zhai et al. 2003) and also in micropropagation (Kawiak and Lojkowska 2004).

However, due to the relatively low fraction of the genome screened with the molecular markers and the moderate sized test population used, these results cannot be interpreted as a final proof that no somaclonal variation has occurred. However, they 
Condello, E. et al. Cryopreservation and genetic stability in wild pear

give us a preliminary information on the genetic stability of the wild pear cryopreserved material and let us to be confident of the possibility of using routinely the encapsulation-dehydration method for long term conservation of Pyrus pyraster.

Acknowledgements: The authors thank Loreta Marinaccio for the skilful assistance in sub-culturing the in vitro material. Research supported by the Italian Ministry of Agriculture. Project RGV-FAO. Public. N. 142

\section{References}

Caboni, E., Tonelli, M.G., Lauri, P., D’Angeli, S. \& Damiano, C. 1999. In vitro shoot regeneration from leaves of wild pear. Plant Cell Tissue Organ Culture 59: 1-7.

Carvalho, L.C., Goulao, L., Oliveira, C., Gonçalves, J.C. \& Amancio, S. 2004. RAPD Assessment for Identification of Clonal Identity and Genetic Stability of in vitro Propagated Chestnut Hybrids. Plant Cell Tissue Organ Culture 77: 23-27.

Dereuddre, J., Scottez, C., Arnaud, Y. \& Duron, M., 1990. Resistance of alginate-coated axillary shoot tips of pear tree (Pyrus communis L., Beurre Hardy) in vitro plantlets to dehydration and subsequent freezing in liquid nitrogen: effect of previous cold hardening Comptes Rendus de l'Académie des Sciences, Paris 310: 317-323.

Dixit, S., Mandal, B.B., Ahuja, S., Srivastava, P.S. 2003. Genetic stability assessment of plants regenerated from cryopreserved embryogenic tissues of Dioscorea bulbifera I. Using RAPD, biochemical and morphological analysis. CryoLetters 24: 77-84.

Engelmann, F. 2004. Plant cryopreservation: progress and prospects. In Vitro Cell Developmental Biology Plant 40: 427-433.

Fabre, J. \& Dereuddre, J. 1990. Encapsulation-dehydration:. A new approach to cryopreservation of Solanum shoot tips. CryoLetters 11: 413-426.

Gonzalez-Arnao, M.T. \& Engelmann, F. 2006. Cryopreservation of plant germplasm using the encapsulation-dehydration technique: review and case study on sugarcane. CryoLetters. 27: 155-68 Hao, Y.J., You, C.X. \& Deng, X.X. 2002. Effects of cryopreservation on developmental competence, cytological and molecular stability of citrus callus. CryoLetters 23: 27-35.

Harding, K. 2004. Genetic integrity of cryopreserved plant cells: a review. CryoLetters 25: 3-22.

Harding, K., Johnston, J. \& Benson, E.E. 2005. Plant and algal cell cryopreservation: issues in genetic

integrity, concepts in 'Cryobionomics' and current European applications:. In: Contributing to a Sustainable Future (eds. I.J. Benett, E. Bunn, H. Clarke \& J.A. McComb) Proc. Australian Branch of the IATPT \& B, Perth, Western Australia: 112-119

Helliot, B., Madur, D., Dirlewanger, E. \& De Boucaud, M.T.
2002. Evaluation of genetic stability in cryopreserved prunus. In Vitro Cell Developmental Biology Plant 38: 493-500.

Kawiak, A. \& Lojkowska, E. 2004. Application of RAPDs in the determination of genetic fidelity in micropropagated Drosera plantlets. In Vitro Cell Developmental Biology Plant. 40: 592-595.

Kleinschmit, J., Stephan, R. \& Wagner, I. 1998. Wild fruit trees (Prunus avium, Malus sylvestris and Pyrus pyraster) genetic resources conservation strategy. In: Noble Hardwoods EUFORGEN. 1996. Updated 2006. Available on the Internet: www.bioversityinternational.org

Lanham, P.G. \& Brennan, R.M. 1999. Genetic characterization of gooseberry (Ribes grossularia subgenus Grossularia) germplasm using RAPD, ISSR and AFLP markers. Journal of Horticultural

Science and Biotechnology 74: 361-366.

Liu, Y.G., Wang, X.Y. \& Liu, L.X. 2004. Analysis of genetic variation in surviving apple shoots following cryopreservation by vitrification. Plant Science 166: 677-685.

Martín, C. \& González-Benito, M.E. 2005. Survival and genetic stability of Dendranthema grandiflora, Tzvelev shoot apices after cryopreservation by vitrification and encapsulation-dehydration. Cryobiology 51: 281-289.

Murashige, T. \& Skoog, F. 1962. Revised Medium for rapid growth and bioassay with Tobacco Tissue Culture Physiologia Plantarum 15: 473-497.

Niino, T. \& Sakai, A. 1992. Cryopreservation of alginatecoated in vitro-grown shoot tips of apple, pear and mulberry. Plant Science 87: 199-206.

Palombi, M.A. \& Damiano, C. 2002. Comparison between RAPDs and SSRs molecular markers to detect genetic variation in kiwifruit (Actinidia deliciosa A., Chev). Plant Cell Report 20: 1061-1066.

Palombi, M.A., Lombardo, B. \& Caboni, E. 2007. In vitro regeneration of wild pear (Pyrus pyraster, Burgsd) clones tolerant to Fe-chlorosis and somaclonal variation analysis by RAPD markers. Plant Cell Report 26: 489-496.

Panis, B. \& Lambardi, M. 2005. Status of cryopreservation technologies in plants (crops and forest trees). International Workshop "The Role of Biotechnology for the Characterisation and Conservation of Crop Forestry Animal and Fishery Genetic Resources". Turin. March 5-7 p. 43-54.

Paul, H., Daigny, G. \& Sangwan-Norreel, B.S. 2000. Cryopreservation of apple (Malus $\mathrm{x}$ domestica Borkh.) shoot tips following encapsulation-dehydration or encapsulation-vitrification Plant Cell Report 19: 768-774.

Plessis, P.C., Leddet, C., Colas, A. \& Dereuddre, J. 1993. Cryopreservation of Vitis vinifera L., cv. Chardonnay shoot tips by encapsulation-dehydration: effect of pretreatment, cooling and postculture conditions. CryoLetters 14: 309-320.

Powell, W., Morgante, M., Doyle, J.J., McNicol, J.W., Tingey, S.V. \& Rafalski, A.J. 1996. Gene pool variation in genus Glycine subgenus Soja revealed by polymorphic nuclear and chloroplast microsatellites. Genetics 144: 793-803.

Quoirin, M. \& Lepoivre, P. 1977. Improved media for in vitro culture of Prunus sp. Acta Horticolturae 78: 437-442.

Rahman, M. \& Rajora O. 2001. Microsatellite DNA somaclonal variation in micropropagated trembling aspen. 


\section{AGRICULTURAL AND FOOD SCIENCE}

Vol. 18 (2009): 136-143.

Plant Cell Reports 20: 531-536

Ryynänen, L. \& Aronen, T. 2005. Vitrification, a complementary cryopreservation method for Betula pendula Roth. Cryobiology 51: 208-19.

Sales, E., Nebauer, S.G., Arrillaga, I. \& Segura, J. 2001. Cryopreservation of Digitalis obscura selected genotypes by encapsulation-dehydration. Planta Medica 67: 833-8.

Shatnawi, M., Engelmann, F., Frattarelli, A., Damiano, C. 1999. Cryopreservation of apices of in vitro plantlets of almond (Prunus dulcis Mill) CryoLetters 20: 13-20.

Venkatachalam, L., Sreedhar, R.V. \& Bhagyalakshmi, N. 2007. Molecular analysis of genetic stability in longterm micropropagated shoots of banana using RAPD and ISSR markers. Electronic Journal of Biotechnology vol. 10, no. 1. Available on the Internet: http://www.ejbiotechnology.info/content/vol10/issue1/ full/12/index.html.

Williams, J.G.K., Kubelik, A.R., Livak, K.J., Rafalski, J.A. \& Tingey, S.V. 1990. DNA polymorphisms amplified by ar- bitrary primers are useful as genetic markers . Nucleic Acids Research 18: 6531-5.

Yamamoto, T., Kimura, T., Shoda, M., Imai, T., Saito, T., Sawamura, Y., Kotobuki, K., Hayashi, T. \& Matsuta, N. 2002. Genetic linkage maps constructed by using an interspecific cross between Japanese and European pear. Theoretical and Applied Genetics. 106: 9-18.

Wu, Y., Zhao, Y., Engelmann, F., Zhou M. 2001a. Cryopreservation of kiwi shoot tips. CryoLetters 22: 277284.

Wu, Y., Zhao, Y., Engelmann, F., Zhou M., Zhang, D., \& Chen, S. 2001b. Cryopreservation of apple dormant buds and shoot tips. CryoLetters 22: $375-380$

Zhai, Z, Wu, Y., Engelmann, F., Chen, R. \& Zhao, Y. 2003. Genetic stability assessments of plantlets regenerated from cryopreserved in vitro cultured grape and kiwi shoot-tips using RAPD. CryoLetters 24: 315-22

Zhao, Y., Wu, Y., Engelmann, F. \& Zhou, M. 2001. Cryopreservation of axillary buds of grape (Vitis vinifera) in vitro plantlets. CryoLetters 22: 321-328. 